\title{
Habitual Caffeine Consumption and its relation to Memory, attention, planning capacity and psychomotor performance across multiple age groups.
}

Citation for published version (APA):

Hameleers, P. A. H. M., van Boxtel, M. P. J., Hogervorst, E., Riedel, W. J., Houx, P. J., Buntinx, F. J. V. M., \& Jolles, J. (2000). Habitual Caffeine Consumption and its relation to Memory, attention, planning capacity and psychomotor performance across multiple age groups. Human Psychopharmacology-Clinical and Experimental, 15, 573-581. https://doi.org/10.1002/hup.218

Document status and date:

Published: 01/01/2000

DOI:

10.1002/hup.218

Please check the document version of this publication:

- A submitted manuscript is the version of the article upon submission and before peer-review. There can be important differences between the submitted version and the official published version of record. People interested in the research are advised to contact the author for the final version of the publication, or visit the $\mathrm{DOI}$ to the publisher's website.

- The final author version and the galley proof are versions of the publication after peer review.

- The final published version features the final layout of the paper including the volume, issue and page numbers.

Link to publication

\footnotetext{
General rights rights.

- You may freely distribute the URL identifying the publication in the public portal. please follow below link for the End User Agreement:

www.umlib.nl/taverne-license

Take down policy

If you believe that this document breaches copyright please contact us at:

repository@maastrichtuniversity.nl

providing details and we will investigate your claim.
}

Copyright and moral rights for the publications made accessible in the public portal are retained by the authors and/or other copyright owners and it is a condition of accessing publications that users recognise and abide by the legal requirements associated with these

- Users may download and print one copy of any publication from the public portal for the purpose of private study or research.

- You may not further distribute the material or use it for any profit-making activity or commercial gain

If the publication is distributed under the terms of Article $25 \mathrm{fa}$ of the Dutch Copyright Act, indicated by the "Taverne" license above, 


\title{
Habitual Caffeine Consumption and its Relation to Memory, Attention, Planning Capacity and Psychomotor Performance across Multiple Age Groups
}

\author{
P. A. H. M. HAMELEERS ${ }^{1}$, M. P. J. VAN BOXTEL ${ }^{1 *}$, E. HOGERVORST ${ }^{3}$, W. J. RIEDEL ${ }^{1}$, \\ P. J. HOUX ${ }^{1}$, F. BUNTINX ${ }^{2}$ and J. JOLLES ${ }^{1}$ \\ ${ }^{1}$ Department of Psychiatry and Neuropsychology, Maastricht University, The Netherlands \\ ${ }^{2}$ Department of General Practice, Maastricht University, The Netherlands \\ ${ }^{3}$ Department of Pharmacology, University of Oxford, UK
}

\begin{abstract}
The present study evaluated the association between habitual caffeine intake via coffee and tea and cognitive performance. This was done as part of a larger research programme into the determinants of cognitive ageing (the Maastricht Aging Study: MAAS). Possible withdrawal effects that may have explained in part the positive association between performance and intake in an earlier study were controlled for. In addition, all cognitive tests in this study were administered under strict laboratory conditions. A group of 1875 healthy adults, stratified for age (range 2481 years), sex, and general ability, were screened for habitual intake of coffee and tea and took part in extensive cognitive testing. Multiple regression analysis with control for age, sex, socio-demographic variables, and substance use showed that habitual caffeine consumption was significantly related to better long-term memory performance and faster locomotor speed. No relationships were found between habitual caffeine consumption and short-term memory, information processing, planning, and attention as measured with the Stroop Test. Moreover, no difference in sensitivity to caffeine intake between different age groups was found, suggesting that caffeine intake did not counteract age-related cognitive decline. Several recommendations are made to improve the design of future studies in this field. Copyright (C) 2000 John Wiley \& Sons, Ltd.
\end{abstract}

KEY WORDS — habitual caffeine consumption; cognition; memory; reaction time; ageing

\section{INTRODUCTION}

Caffeine has long been of interest, because it is consumed daily by many people all over the world with relatively few side-effects (Klatsky et al., 1993). Acute dose studies have been performed to investigate its effects on cognitive performance. Acute caffeine intake has been shown to improve reaction times (Jacobson and Edgley, 1987; Swift and Tiplady, 1988) and performance on vigilance tasks (Yu et al., 1991) even with amounts as low as 32 mg (Lieberman et al., 1987). Its effects on memory are still ambiguous. It has been reported that acute consumption of $2 \mathrm{mg} / \mathrm{kg}$ and $4 \mathrm{mg} / \mathrm{kg}$ caffeine impaired the encoding of stimuli in working mem-

\footnotetext{
* Correspondence to: M. P. J. van Boxtel, EURON, Maastricht University, Department of Psychiatry and Neuropsychology, P.O. Box 616, 6200 MD Maastricht, The Netherlands. Tel: +31-43-388-1028. Fax: +31-43-367-1096. e-mail: martin. vanboxtel@NP.Unimaas.NL.
}

ory in women compared to placebo (Erikson et al., 1985). However, other authors found that acute ingestion of $100 \mathrm{mg}$ caffeine improved memory function (Terry and Phifer, 1986) or had no effect (125 mg and $250 \mathrm{mg}$; Foreman et al., 1989; Mitchell and Redman, 1992). Its effect on attention as measured with the Stroop Test is also unclear. Acute ingestion of 125 and $250 \mathrm{mg}$ caffeine impaired performance on the Stroop Test compared to placebo in one study (Foreman et al., 1989) but had no effect in another (Edwards et al., 1996).

Another important aspect is investigating the relationship between habitual caffeine consumption and cognitive performance and whether tolerance develops to the effects of caffeine. Studies in this field are scarce. Jarvis found significant linear relationships between habitual caffeine consumption and both memory performance and reaction time, i.e. higher habitual caffeine intake was associated with more words recalled in an incidental learning task and with faster reaction times in a 
reaction time task (in both simple and complex conditions). However, it has been argued by Rogers and Dernoncourt (1998) that the results reported by Jarvis (1993) may have been due to caffeine withdrawal, because nonusers had markedly faster reaction times in a choice reaction time task than low-to-moderate users.

It has been suggested that caffeine may act as a cognition enhancer and thus could be used by older people to overcome age-related cognitive decline (for a review see Riedel and Jolles, 1996). Riedel et al. (1995) found that acute consumption of $250 \mathrm{mg}$ caffeine improved memory impairment induced by scopolamine, a model that is used to produce memory deficits in normal individuals. Hogervorst et al. (1998) investigated the acute effects of caffeine in three age groups and found that acute caffeine ingestion improved performance of a memory task in middle-aged individuals only. However, it turned out that the middle-aged participants habitually consumed twice as much caffeine as the younger and the older participants. The authors hypothesized that the results were attributable to the higher habitual caffeine use in the middle-aged group. Jarvis (1993) reported age differences in the sensitivity to habitual caffeine consumption. Overall, a higher level was significantly related to better performance on a reaction time task, but the improvement was greatest in the older participants. This result suggests that habitual caffeine use may have beneficial effects on age-related cognitive decline.

The present study was performed to study the relationship between habitual caffeine consumption and cognitive and psychomotor performance in a large population sample under laboratory conditions. Participants were offered a cup of coffee or tea prior to testing to ensure that their caffeine levels were 'normal', i.e. there were no abstinence or withdrawal effects. Moreover, participants of different ages were included to investigate differences in sensitivity to caffeine and to explore whether the effect of caffeine is modified by age.

\section{MATERIALS AND METHODS}

\section{Participants}

This study is a part of a larger longitudinal study into the biological and psychological determinants of cognitive ageing (Maastricht Aging Study; Jolles et al., 1995). Healthy participants (1904) were recruited from a register of general practices in the southern part of the Netherlands (Metsemakers et al., 1992). Participants with cerebrovascular disease, chronic neurological pathology, and mental retardation or psychotropic drug use were excluded. The participants were stratified for age, sex, and general ability. Participants filled in a questionnaire at home with respect to socio-demographic status and health characteristics and were then invited to the laboratory for neuropsychological testing. Participants (1875) ranging from 24 to 81 years old (mean age $=52 \cdot 03 \pm 16 \cdot 6$ years) completed the tests.

The Medical Ethics Committee of Maastricht University, the Netherlands, approved this study. Prior to the start of the study all participants gave their written informed consent.

\section{Caffeine consumption}

The questionnaire asked participants about their daily caffeine consumption. In answer to the question 'Do you drink coffee?' participants could tick one of the following answers: 'No', 'Yes, 1 to 3 cups a day', 'Yes, 4 to 6 cups a day', 'Yes, 7 to 10 cups a day', and 'Yes, more than 10 cups a day'. A similar question was asked about tea. The midpoints of these ranges were used in the statistical analyses (i.e. $0,2,5,8.5$ and 11 cups). Total daily caffeine consumption was expressed as number of cups of coffee equivalents consumed per day. This was calculated as $\left(85 \times M_{\text {coffee }}+30 \times M_{\text {tea }}\right) / 85$, in which the weights assigned to the mean habitual coffee and tea consumption are the actual average caffeine contents of coffee and tea according to industrial standards, namely $85 \mathrm{mg}$ and $30 \mathrm{mg}$ caffeine, respectively (Willems, 1986). The scale ranged from 0 to 8 cups of coffee equivalents (values higher than 8 were assigned the value 8 , which is similar to the procedure used by Jarvis, 1993).

Before the cognitive tests were done, participants were offered a cup of coffee or tea according to their own preferences (with optional sugar or milk) to maintain a preferred internal level of caffeine and to control for potential withdrawal effects.

\section{Control variables}

A number of potentially confounding demographic variables were introduced into the model. Age (in years), sex, and educational level, housing tenure (rented/not rented), and occupation (blue-collar/ white-collar), smoking (yes/no), alcohol consumption (number of standard units per week), and 
perceived health were found to be correlated with habitual caffeine consumption and task performance.

Level of education was scored on an 8-point scale (De Bie, 1987), ranging from primary school level to university degree. This scale was reduced to three levels: low, medium, and high education. The latest occupation was coded according to a frequently used coding system in the Netherlands (Centraal Bureau voor de Statistiek, 1985). These scores were aggregated into blue-collar and white-collar occupation (Erickson et al., 1979; Van Loon et al., 1994). The participants were asked to score their subjective health on a 5-point scale from 1 (very poor) to 5 (very good). This scale was transformed into a dummy variable that indicated good-to-very-good (1) versus poor-to-very poor (0).

\section{Cognitive tasks}

During the test session the following tasks were performed to measure memory function, reaction time, planning capacity, and attention.

Visual Verbal Learning Test (VVLT) This is a computerized, visual version of a test of secondary memory (Brand and Jolles, 1985). In five consecutive trials, a list of 15 monosyllabic nouns, similar in frequency, was presented on a computer screen. The words appeared at a rate of one per second with an internal of $2 \mathrm{~s}$. After word presentation, the participants were asked to recall these words. Twenty minutes after the final trial, they were asked to recall the words again. The number of words recalled after trial one was taken as a measure of memory load and the cumulative number of words recalled over the five immediate recall trials was taken as a measure of learning capacity. The number of words recalled during delayed recall relative to the maximum number during the immediate recall was taken as a measure of retrieval from long-term memory. This was computed as VVLTdelay/VVLTmax) $\times 100$ per cent, in which VVLTdelay is the number of words reproduced during the delayed recall trial and VVLTmax is the immediate recall trial with the highest score.

Motor Choice Reaction Test (MCRT) This is a computer test in which measurements are obtained with a push-button panel (Houx and Jolles, 1993). It contains one central red button and five surrounding white target buttons, laid out in a $180^{\circ}$ arc, all at a distance of $6 \mathrm{~cm}$ from the red button.
The participants were requested to hold down the red button with the index finger of the preferred hand as long as no white button was lit. As soon as a white button was illuminated, the participants had to release the red button and briefly press the lit button and then return to the red central button. Two subsequent task conditions, of increasing difficulty, were used. These were simple reaction time (SRT), in which only the upper button was lit and choice reaction time (CRT), in which one of a defined set of three buttons was lit. Both conditions consisted of 30 button presses. The following dependent variables were recorded: the median reaction time (time from stimulus onset until the lit button was pressed) and the median movement time (time from release of the hold button until the response button was pressed).

Letter-Digit Substitution Test (LDST) This is a modification of the procedurally identical DigitSymbol Substitution Test (Smith, 1968). The number of correctly completed letters in $90 \mathrm{~s}$ was used as the dependent variable.

Fluency This is a test for strategy-driven retrieval of information from semantic memory (Luteijn and van der Ploeg, 1983). Participants were asked to produce as many animal names as possible in $1 \mathrm{~min}$. The number of correct responses was taken as the dependent variable.

Concept Shifting Test (CST) This is an adaptation of the Trail Making Test (Reitan, 1958). On each test sheet, 16 small circles (diameter $15 \mathrm{~mm}$ ) were grouped in a larger circle (diameter $16 \mathrm{~cm}$ ). In the smaller circles the test items appeared in a fixed random order. The test items were numbers (CSTA), letters (CST-B), or both (CST-C). Participants were asked to cross out the items in the correct ascending order as quickly as possible (Jolles et al., 1995). The dependent variable was the relative contribution of the need to shift between two concepts. This was computed as (tCST-C $-0.5 \times$ $(\mathrm{tCST}-\mathrm{A}+\mathrm{tCST}-\mathrm{B})) /(0 \cdot 5 \times(\mathrm{tCST}-\mathrm{A}+\mathrm{tCST}-\mathrm{B})) \times$ 100 per cent, in which tCST-A, tCST-B and t-CST$\mathrm{C}$ refer to the times needed to complete the operations.

Stroop Color-Word Test This is a test with three different subtasks, each displaying $10 \times 10$ items (Nehemkis and Lewinson, 1972). In subtask I colour names (red, yellow, green and blue) printed in black ink were to be read as quickly as possible. In 
subtask II, the colour of different patches was to be named as quickly as possible. In subtask III, colour names were printed in incongruously coloured ink. Participants were asked to name the colour of the ink in which the words were printed. Time to complete subtask I was taken as a measure of simple response (reading) speed. Interference, as a measure of attention, was computed as (tSTR-III $-0.5 \times$ $($ tSTR-I + tSTR-II $)) /(0 \cdot 5 \times($ tSTR-I + tSTR-II $)) \times$ 100 per cent, in which tSTR-I to tSTR-III refer to the time needed to complete subtasks I-III, respectively (Houx et al., 1993).

\section{Statistics}

Multiple hierarchical regression analysis was used to test the hypothesis that habitual caffeine consumption predicts performance on the cognitive tasks in a dose-response manner. Both linear and quadratic relationships were investigated. Age, sex, educational level, blue-collar or white-collar occupation, housing tenure, smoking, alcohol, and perceived health were entered in the model on step 1 . In the next two steps caffeine intake and caffeine intake squared were entered in order to determine linear or quadratic relationships between caffeine and the dependent variables. Residuals were inspected for systematic trends, but none was identified. For statistical analysis SPSS 6.1 for Macintosh was used. $P$-values of 0.05 or less were considered statistically significant.

\section{RESULTS}

\section{Descriptives}

Coffee and tea consumption were inversely correlated $(R=-0.29 ; p<0.001 ; n=1875)$. One hundred and sixty-one participants did not drink coffee on a daily basis, as opposed to 644 participants who did not drink tea. Two hundred and seventy-two participants drank seven or more cups of coffee a day, whereas only 38 participants drank seven or more cups of tea a day (see Tables 1 and 2 ). The zero-order correlations between habitual coffee, tea, and caffeine intake and the confounding variables are shown in Table 3. It emerged that men drank more coffee than women and that smokers drank more coffee than nonsmokers. In addition, coffee consumption was positively correlated with alcohol consumption, whereas the opposite was found for tea consumption. Furthermore, tea consumption, but not coffee, increased with increasing age. Blue-collar occupation was positively correlated with higher coffee consumption. Overall, the direction of the correlations between the confounding variables and habitual caffeine consumption and habitual coffee consumption were the same.

\section{Results of the cognitive tests}

There was no significant interaction between caffeine intake and age on cognitive task performance, which suggests that there are no age differences in sensitivity to caffeine. In Table 4 the values of the standardized regression coefficient $(\beta)$ of each variable in the model are given, including the proportion of explained variance $\left(R^{2}\right)$ after each step. Overall, the results show that increasing age was strongly associated with poorer task performance, and that higher educational level was associated with better performance. The cognitive test performance of men and women was different. Men, for instance, had faster movement and total reaction times on the MCRT, whereas women performed better on the VVLT. Smoking behaviour and habitual alcohol consumption were both associated with speed-related performance measures, such as reading speed in subtask I of the Stroop Test and reaction time during the MCRT. Higher habitual alcohol consumption was related to faster responses and smoking with a slower reading speed.

Overall, habitual caffeine consumption was significantly related to movement time on the MCRT for both conditions. A faster movement time was associated with a higher daily caffeine consumption, as shown in Figure 1. Furthermore, a significant quadratic relationship emerged between habitual caffeine consumption and simple reading speed, as measured with subtask I of the Stroop Test. Reading speed improved up to five caffeine units and then decreased. Habitual caffeine consumption was positively related to delayed recall performance.

\section{DISCUSSION}

In this study, higher habitual caffeine consumption was found to be associated with faster simple response speed and better long-term memory. However, habitual caffeine intake was not significantly associated with short-term memory performance, planning capacity, information processing or attention. No differences in sensitivity to habitual 
Table 1. Habitual coffee consumption by the demographic variables

\begin{tabular}{llllll}
\hline & \multicolumn{5}{c}{ Habitual number of cups of coffee per day } \\
\cline { 2 - 6 } & \multicolumn{1}{c}{$\begin{array}{c}0 \\
\end{array}$} & $\begin{array}{c}1-3 \\
n=161)\end{array}$ & $\begin{array}{c}4-6 \\
n=717)\end{array}$ & $\begin{array}{c}7-10 \\
(n=735)\end{array}$ & $\begin{array}{c}(n=211) \\
10 \text { or more } \\
(n=61)\end{array}$ \\
\hline Age (in years) & $45 \cdot 0$ & $53 \cdot 7$ & $53 \cdot 4$ & $47 \cdot 9$ & $46 \cdot 2$ \\
Sex (\% male) & $45 \cdot 3$ & $45 \cdot 3$ & $53 \cdot 2$ & $54 \cdot 0$ & $65 \cdot 6$ \\
Educational level (\% high educ.) & $27 \cdot 3$ & $22 \cdot 0$ & $22 \cdot 2$ & $21 \cdot 3$ & $13 \cdot 1$ \\
Housing tenure (\% not rented) & $53 \cdot 6(153)$ & $59 \cdot 3(673)$ & $61 \cdot 5(685)$ & $61 \cdot 0(200)$ & $53 \cdot 4(58)$ \\
Occupation (\% white-collar) & $57 \cdot 4(108)$ & $58 \cdot 6(534)$ & $54 \cdot 6(524)$ & $48 \cdot 0(144)$ & $32 \cdot 8(36)$ \\
Cigarette smokers (\% smokers) & $5 \cdot 4$ & $25 \cdot 5$ & $38 \cdot 5$ & $22 \cdot 2$ & $8 \cdot 4$ \\
Alcohol (number of units per week) & $10 \cdot 8(108)$ & $11 \cdot 0(569)$ & $11 \cdot 0(604)$ & $12 \cdot 1(182)$ & $15 \cdot 8(49)$ \\
Health (\% good-to-very-good) & $73 \cdot 1$ & $70 \cdot 3$ & $70 \cdot 3$ & $67 \cdot 3$ & $63 \cdot 9$ \\
Tea (number of cups per day) & $3 \cdot 1$ & $2 \cdot 1$ & $1 \cdot 6$ & $1 \cdot 0$ & $0 \cdot 7$ \\
\hline
\end{tabular}

Table 2. Habitual tea consumption by the demographic variables

\begin{tabular}{llcccc}
\hline & \multicolumn{5}{c}{ Usual number of cups of tea per day } \\
\cline { 2 - 6 } & \multicolumn{1}{c}{$\begin{array}{c}0 \\
(n=644)\end{array}$} & $\begin{array}{c}1-3 \\
(n=984)\end{array}$ & $\begin{array}{c}4-6 \\
(n=219)\end{array}$ & $\begin{array}{c}7-10 \\
(n=30)\end{array}$ & $\begin{array}{c}10 \text { or more } \\
(n=8)\end{array}$ \\
\hline Age (in years) & $50 \cdot 8$ & $51 \cdot 6$ & $57 \cdot 3$ & $52 \cdot 3$ & $41 \cdot 5$ \\
Sex (\% male) & $60 \cdot 4$ & $44 \cdot 8$ & $43 \cdot 8$ & $46 \cdot 7$ & $25 \cdot 0$ \\
Educational level (\% high educ.) & $20 \cdot 8$ & $22 \cdot 3$ & $24 \cdot 6$ & $26 \cdot 6$ & $37 \cdot 5$ \\
Housing tenure (\% not rented) & $59 \cdot 9(601)$ & $59 \cdot 7(928)$ & $61 \cdot 7(206)$ & $46 \cdot 4(28)$ & $50 \cdot 0(8)$ \\
Occupation (\% white-collar) & $51 \cdot 2(478)$ & $57 \cdot 1(706)$ & $63 \cdot 0(143)$ & $72 \cdot 3(18)$ & $66 \cdot 6(3)$ \\
Cigarette smokers (\% smokers) & $45 \cdot 5$ & $46 \cdot 3$ & $5 \cdot 7$ & $1 \cdot 6$ & $0 \cdot 8$ \\
Alcohol (number of units per week) & $13 \cdot 0(526)$ & $10 \cdot 3(793)$ & $10 \cdot 5(166)$ & $9 \cdot 2(21)$ & $12 \cdot 3(6)$ \\
Health (\% good-to-very-good) & $69 \cdot 0$ & $71 \cdot 3$ & $70 \cdot 2$ & $46 \cdot 6$ & $75 \cdot 0$ \\
Coffee (number of cups per day) & $5 \cdot 1$ & $3 \cdot 6$ & $2 \cdot 9$ & $2 \cdot 1$ & $2 \cdot 2$ \\
\hline
\end{tabular}

Table 3. Zero-order correlations between coffee, tea, caffeine, and the confounders in the study

\begin{tabular}{|c|c|c|c|c|c|c|c|c|}
\hline & $\begin{array}{c}\text { Age } \\
\text { (years) }\end{array}$ & Education & $\operatorname{Sex} \dagger$ & Smokingt: & $\begin{array}{c}\text { Alcohol } \\
\text { (units/week) }\end{array}$ & $\begin{array}{c}\text { Subjective } \\
\text { health§ }\end{array}$ & $\begin{array}{l}\text { Housing } \\
\text { tenureq }\end{array}$ & Occupation \\
\hline Coffee & $-0 \cdot 04$ & -0.02 & $-0.09 * * *$ & $0 \cdot 28 * * *$ & $0.08 * * *$ & -0.03 & -0.02 & $0.06^{* *}$ \\
\hline Tea & $0.07 * * *$ & $0 \cdot 01$ & $0 \cdot 11 * * *$ & $-0 \cdot 11 * * *$ & $-0.08 * * *$ & -0.02 & $0 \cdot 02$ & $-0 \cdot 01$ \\
\hline Caffeine & $0 \cdot 01$ & -0.03 & $-0 \cdot 05^{*}$ & $0 \cdot 28 * * *$ & $0 \cdot 05^{*}$ & $-0 \cdot 04$ & $-0 \cdot 02$ & $0 \cdot 05^{*}$ \\
\hline
\end{tabular}

$* p<0.05 ; * * p<0.01 ; * * * p<0.001$.

$\dagger$ Sex: $\operatorname{man}=1$, woman $=2$.

$\$$ Smoking: no $=0$, yes $=1$.

$\S$ Subjective health: poor-to-very-poor $=0$, good-to-excellent $=1$.

$\uparrow$ Housing tenure: owner-occupied $=0$, rented $=1$.

"Occupation: white-collar $=0$, blue-collar $=1$.

caffeine consumption on cognitive test performance between different ages were found.

The improvement in long-term memory performance associated with a higher daily caffeine consumption suggests that habitual caffeine intake is related to better storage or retrieval from longterm memory, as was earlier hypothesized by Loke (1988). Loke's results showed no effect of acute 
P. A. H. M. HAMELEERS $E T A L$.

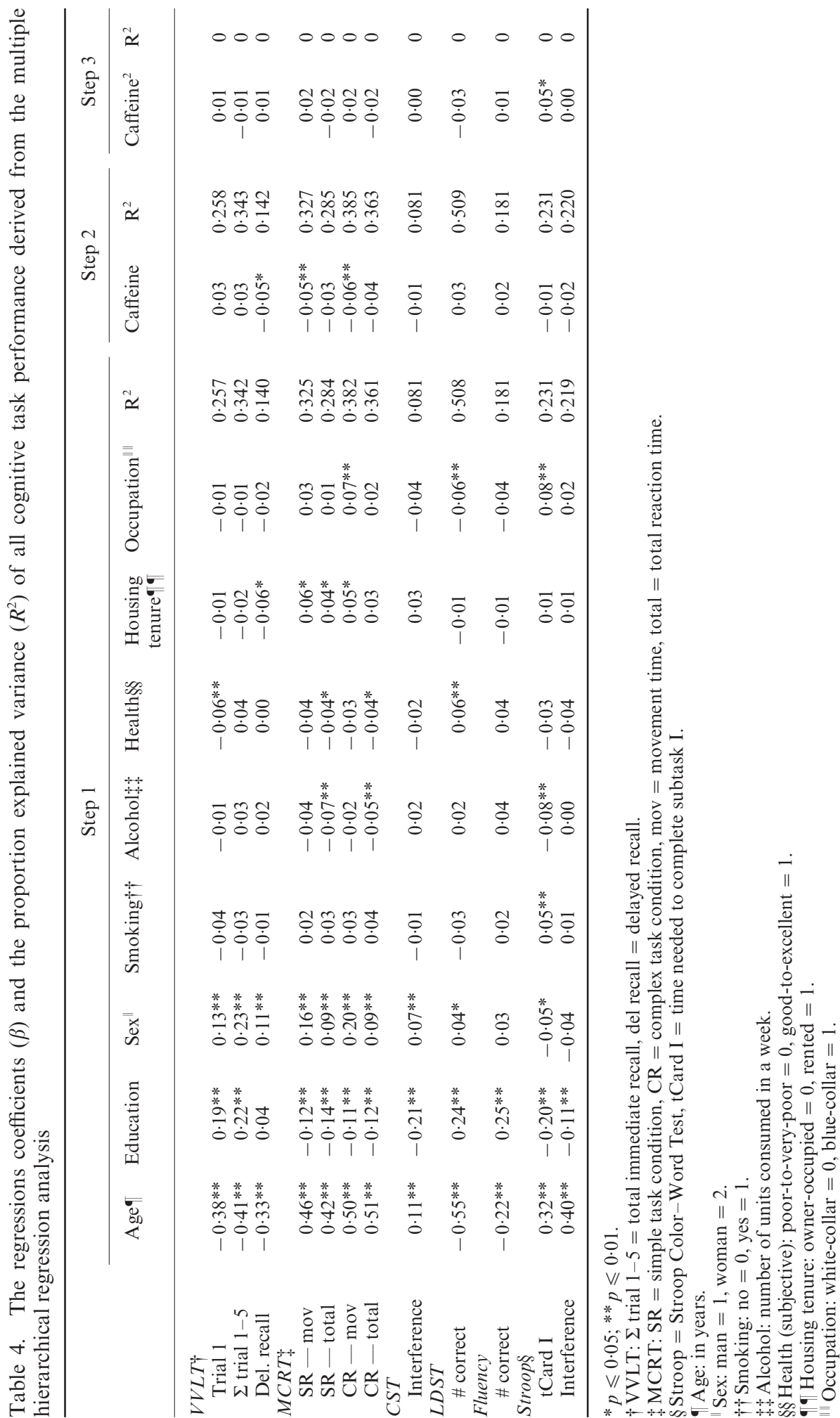

Copyright (C) 2000 John Wiley \& Sons, Ltd.

Hum. Psychopharmacol. Clin. Exp. 15, 573-581 (2000) 


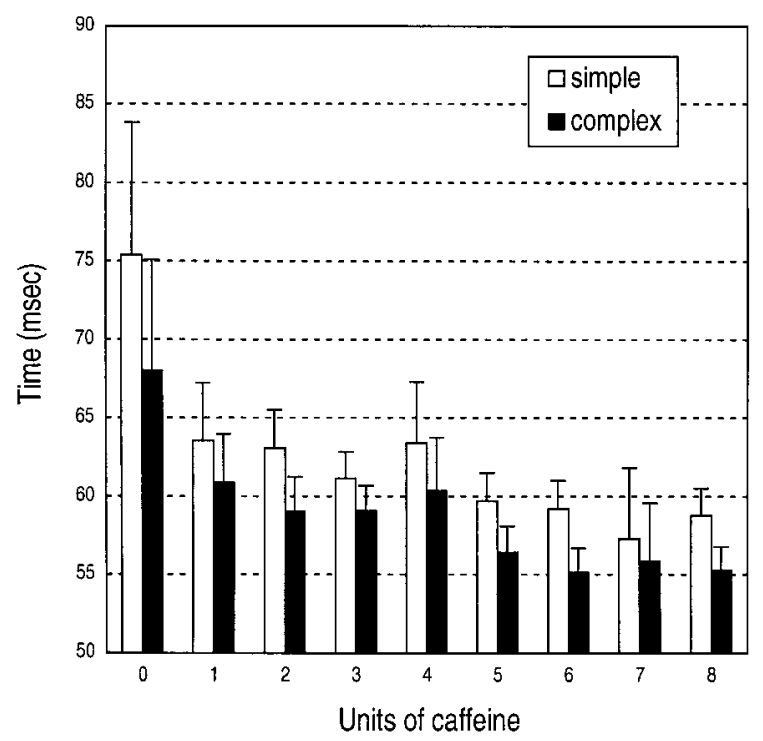

Figure 1. The adjusted movement times of the MCRT in the simple and the complex task condition as a function of habitual caffeine consumption

caffeine intake on working, short-term, and longterm memory in different task paradigms. However, higher habitual caffeine consumption was shown to be related to better delayed recall performance, in that moderate-to-high habitual users (mean of 710 $\mathrm{mg} /$ week) recalled more words than did low habitual users (mean of $178 \mathrm{mg} /$ week). Jarvis (1993) also found a positive relationship between habitual caffeine consumption and memory in a large population sample.

In the present study, higher habitual caffeine intake was also related to reaction time, in accordance with Jarvis (1993). More specifically, a faster movement time (and not total reaction time, which includes an information processing component) was associated with a higher habitual caffeine intake. This result, together with the finding that habitual caffeine intake was positively associated with reading speed as measured with Stroop card I (with an optimum of five cups of caffeine units per day), is consistent with the general assumption that caffeine is a mild CNS stimulant that increases arousal (Nehlig et al., 1992). Acute caffeine ingestion increases the extracellular levels of acetylcholine and serotonin by binding to adenosine receptors (Carter et al., 1995; Nehlig et al., 1992). These neurotransmitters are involved in memory and locomotor activity. Chronic caffeine consumption leads to an increase in adenosine receptor

Copyright (C) 2000 John Wiley \& Sons, Ltd. numbers in animal models and to modification of the sensitivity of cholinergic neurons to caffeine, but the actual neurochemical basis for the behavioural and cognitive effects of habitual caffeine consumption are not yet fully understood (Nehlig et al., 1992).

The absence of a relationship between habitual caffeine use and performance in the other cognitive domains may indicate that either no relationship exists or that tolerance develops to the properties of caffeine. To the best of our knowledge, the relationship between planning capacity and habitual caffeine consumption and attention, as measured with the Stroop Test, and habitual caffeine consumption have not been investigated in earlier studies. Acute dose studies have not demonstrated an effect of caffeine on planning (Lieberman et al., 1987; Streufert et al., 1995). Acute ingestion of 125 $\mathrm{mg}$ and $250 \mathrm{mg}$ caffeine was not found to affect attention, as measured in the Stroop paradigm, although Foreman et al. (1989) reported that an acute dose of $250 \mathrm{mg}$ caffeine impaired performance on the Stroop compared to placebo.

Some limitations of the present study have to be taken into consideration in future research in order to improve the specificity of predictions about the relationship between caffeine intake and cognitive performance. First, the present study did not distinguish between caffeinated and decaffeinated coffee, or caffeinated tea and herbal tea for that matter, which may have biased the results. Secondly, the possibility exists that yet another substance in the beverages was responsible for the results found. Hindmarch et al. (1998) recently reported subtle but not significant differences in the effects of tea and coffee. They reported a major difference between caffeinated beverages and hot water or decaffeinated tea on a measure of overall CNS activity, the critical flicker fusion (CFF). Furthermore, they demonstrated a trend toward better performance on the CFF after tea consumption as opposed to coffee consumption (the beverages used had a standardized caffeine content of $100 \mathrm{mg}$ ). Thirdly, a complex relationship may exist between caffeine intake, smoking, and habitual alcohol consumption, although the present study controlled for the use of nicotine and alcohol alone. In an acute dose study, Kerr et al. (1991) reported improved motor reaction times due to nicotine, caffeine, or a combination of nicotine and caffeine. Both nicotine and caffeine alone significantly affected short-term memory. No additive effects were found with alcohol. In another acute dose study, Hasenfratz et al. 
(1993) did find an additive effect of alcohol and caffeine on speed of information processing, but only when caffeine was ingested before the alcohol was absorbed. Finally, older individuals may moderate their caffeine intake to compensate for their increased sensitivity to the compound, or perhaps because of experienced or presumed adverse effects, such as reduced sleep quality. It is uncertain whether the consumption profile of older people is optimal for experiencing a beneficial effect of caffeine in daily life. These questions need to be explored further before definite conclusions can be drawn about the net effect of caffeine use on cognitive ageing.

Jarvis (1993) reported a much stronger relationship of caffeine than was found in the present study, although the cognitive domains involved are the same. There are several explanations possible for this difference in significance. The results of Jarvis (1993) may have been biased due to the withdrawal effects of caffeine at the moment of cognitive testing, as has recently been argued by Rogers and Dernoncourt (1998). In addition, the participants in the Jarvis study were not tested under laboratory conditions. Furthermore, in the present study the participants were stratified for age, sex, and educational level, which created a more controlled experimental setting for investigating the relationship between habitual caffeine intake and cognitive performance. Finally, the population of Jarvis (1993) consumed more tea than coffee, whereas the opposite was found in the present study, which would affect the composition of the overall intake measure of caffeine. In the present study, it was not possible to study the relationship between the individual beverages and cognitive performance, due to the skewed distribution of tea consumption (see also Table 2). Only 14 per cent of the population drank more than three cups of tea per day.

In short, there is a relationship between habitual caffeine consumption and memory function (more specifically, long-term memory) and reaction time (more specifically, locomotor speed), although the impact of the substance may be less pronounced than has been suggested earlier. Future research should focus on studying long-term caffeine intake and cognitive performance prospectively. In a longitudinal study, it should be possible to relate habitual caffeine use to changes in cognitive performance over time. In addition, it may be important to include more information about specific aspects of caffeine use, such as the intake related to the time of day, the experienced effects of caffeine consumption, and the possible reasons behind a change in caffeine intake.

\section{REFERENCES}

Brand N, Jolles J. 1985. Learning and retrieval rate of words presented auditory and visually. J Gen Psychol 112: $201-210$.

Carter AJ, O'Connor WT, Carter MJ, Ungerstedt U. 1995. Caffeine enhances acetylcholine release in the hippocampus in vivo by a selective interaction with adenosine A1 receptors. J Pharmacol Exp Therapeut 273: 637-642.

Centraal Bureau voor de Statistiek. 1985. Beroepenclassificatie 1984 [Job Classification 1984]. CBS: Voorburg, The Netherlands.

De Bie SE. 1987. Standaardvragen 1987: Voorstellen voor Uniformering van Vraagstellingen naar Achtergrondkenmerken en Interviews [Standard Questions 1987: Proposal for Uniformisation of Questions Regarding Background Variables and Interviews]. Leiden University Press: Leiden, The Netherlands.

Edwards S, Brice C, Craig C, Penri-Jones R. 1996. Effects of caffeine, practice, and mode of presentation on Stroop task performance. Pharmacol Biochem Behav 54: $309-315$.

Erickson R, Goldthorpe JH, Portocarero L. 1979. Intergenerational class mobility in three western countries: England, France and Sweden. Br J Sociol 30: 425-441.

Erickson GC, Hager LB, Houseworth C, Dungan J, Petros T, Beckwith BE. 1985. The effects of caffeine on memory for word lists. Physiol Behav 35: 47-51.

Foreman N, Barraclough S, Moore C, Mehta A, Madon M. 1989. High doses of caffeine impair performance of a numerical version of the Stroop task in men. Pharmacol Biochem Behav 32: 399-403.

Hasenfratz M, Bunge A, Dal Pra G, Battig K. 1993. Antagonistic effects of caffeine and alcohol on mental performance parameters. Pharmacol Biochem Behav 46: 463-465.

Hindmarch I, Quinlan PT, Moore KL, Parkin C. 1998. The effect of black tea and other beverages on aspects of cognition and psychomotor performance. Psychopharmacology 139: 230-238.

Hogervorst E, Riedel WJ, Schmitt JAJ, Jolles J. 1998. Caffeine improves memory performance during distraction in middle-aged, but not in young or old subjects. Hum Psychopharmacol 13: 277-284.

Houx PJ, Jolles J. 1993. Age-related decline of psychomotor speed: effects of age, brain health, sex and education. Percep Motor Skills 76: 195-211.

Houx PJ, Jolles J, Vreeling FW. 1993. Stroop interference: aging effects assessed with the Stroop ColorWord test. Exp Aging Res 19: 209-224.

Jacobson BH, Edgley BM. 1987. Effects of caffeine on simple reaction time and movement time. Aviation, Space, Environ Med 58: 1153-1156. 
Jarvis MJ. 1993. Does caffeine intake enhance absolute levels of cognitive performance? Psychopharmacology 110: $45-52$.

Jolles J, Houx PJ, Van Boxtel MPJ, Ponds RWHM (eds). 1995. Maastricht Aging Study: Determinants of Cognitive Aging. Neuropsych Publishers: Maastricht, The Netherlands.

Kerr JS, Sherwood N, Hindmarch I. 1991. Separate and combined effects of the social drugs on psychomotor performance. Psychopharmacology 104: 113-119.

Klatsky AL, Armstrong MA, Friedman GD. 1993. Coffee, tea and mortality. Ann Epidemiol 3: 375-381.

Lieberman HR, Wurtman RJ, Emde GG, Roberts C, Coviella ILG. 1987. The effects of low doses of caffeine on human performance and mood. Psychopharmacology 92: 308-312.

Loke WH. 1988. Effects of caffeine on mood and memory. Physiol Behav 44: 367-372.

Luteijn F, van der Ploeg FAE. 1983. Handleiding Groninger Intelligentie Test (GIT) [Manual Groningen Intelligence Test]. Swetz and Zeitlinger: Lisse, The Netherlands.

Metsemakers JFM, Höppener P, Knottnerus JA, Kocken RJJ, Limonard CBG. 1992. Computerized health information in the Netherlands: a registration network of family practices. Br J Gen Pract 42: 102-106.

Mitchell PJ, Redman JR. 1992. Effects of caffeine, time of day and user history on study related performance. Psychopharmacology 109: 121-126.

Nehemkis AM, Lewinson PM. 1972. Effect of left and right cerebral lesions in the naming process. Percept Motor Skills 35: 787-798.

Nehlig A, Daval JL, Debry G. 1992. Caffeine and the central nervous system: mechanisms of action, biochemical, metabolic and psychostimulant effects. Brain Res Rev 17: 139-170.

Reitan RM. 1958. Validity of the Trail Making Test as an indication of organic brain damage. Percept Motor Skills 8: 271-276.

Riedel W, Hogervorst E, Leboux R, Verhey F, Van Praag H, Jolles J. 1995. Caffeine attenuates scopolamineinduced memory impairment in humans. Psychopharmacology 122: 158-168.

Riedel W, Jolles J. 1996. Cognition enhancers in agerelated cognitive decline. Drugs Aging 8: 245-274.

Rogers PJ, Dernoncourt C. 1998. Regular caffeine consumption: a balance of adverse and beneficial effects of mood and psychomotor performance. Pharmacol Biochem Behav 59: 1039-1045.

Smith A. 1968. The Symbol Digit Modalities Test: a neuropsychological test for economic screening of learning and other cerebral disorders. Learn Disord 36: 83-91.

Streufert S, Pogash R, Miller J, Gingrich D, Landis R, Lonardi L, Severs W, Roache JD. 1995. Effects of caffeine deprivation on complex human functioning. Psychopharmacology 118: 377-384.

Swift CG, Tiplady B. 1988. The effects of age on the response to caffeine. Psychopharmacology 94: 29-31.

Terry WS, Phifer B. 1986. Caffeine and memory performance on the AVLT. J Clin Psychol 42: 860-863.

Van Loon AJ, Goldbohm RA, Van Den Brandt PA. 1994. Socioeconomic status and breast cancer incidence: a prospective cohort study. Int J Epidemiol 23: 899-905.

Warburton DM. 1995. Effects of caffeine on cognition and mood without caffeine abstinence. Psychopharmacology 119: 66-70.

Willems MI. 1986. Koffie, thee en caffeine [Coffee, tea and caffeine]. Voeding in de Praktijk [Food in Practice] VII(B6): 1-13.

Yu G, Maskray V, Jackson SHD, Swift CG, Tiplady B. 1991. A comparison of the central nervous system effects of caffeine and theophylline in elderly subjects. Br J Clin Pharmacol 32: 341-345. 